UNIVERSITY OF GOTHENBURG

SCHOOL OF BUSINESS, ECONOMICS AND LAW

WORKING PAPERS IN ECONOMICS

No 519

\title{
Group Decision Making Under Risk: An Experiment with Student Couples
}

\author{
Haoran He \\ Peter Martinsson \\ Matthias Sutter
}

December 2011

ISSN 1403-2473 (print)

ISSN 1403-2465 (online) 


\title{
Group Decision Making Under Risk: An Experiment with Student Couples ${ }^{\S}$
}

\author{
Haoran $\mathrm{He}^{*}$ \\ School of Economics and Business Administration, Beijing Normal University, China \\ Department of Economics, University of Gothenburg, Sweden \\ Peter Martinsson ${ }^{\dagger}$ \\ Department of Economics, University of Gothenburg, Sweden \\ Matthias Sutter ${ }^{\ddagger}$ \\ Department of Public Economics, University of Innsbruck, Austria \\ Department of Economics, University of Gothenburg, Sweden
}

\begin{abstract}
In an experiment, we study risk-taking of cohabitating student couples, finding that couples' decisions are closer to risk-neutrality than single partners' decisions. This finding is similar to earlier experiments with randomly assigned groups, corroborating external validity of earlier results.
\end{abstract}

JEL Classification: C91; C92.

Key words: Risk experiment; Student couples; Group decision making.

\footnotetext{
$\S$ Ackowledgements: We would like to thank an anonymous referee for very helpful comments. Financial support from the Jan Wallander and Tom Hedelius Foundation, from Wilhelm and Martina Lundgrens Science Foundation and from the Swedish Research Council (Vetenskapsrådet) is gratefully acknowledged.

* School of Economics and Business Administration, Beijing Normal University, Xinjiekouwai Street 19, 100875 Beijing, China. Phone: +86(10)58807847; E-mail: haoran.he@bnu.edu.cn.

${ }^{\dagger}$ Department of Economics, University of Gothenburg, Box 640, 40530 Gothenburg, Sweden. Phone: + 46(31)7865255; E-mail: peter.martinsson@economics.gu.se.

₹ Department of Public Finance, University of Innsbruck, Universitaetsstrasse 15, A-6020 Innsbruck, Austria. Phone: +43(512)5077170; E-mail: matthias.sutter@uibk.ac.at.
} 


\section{Introduction}

Many important decisions in human life are made by groups rather than individuals. Think of families, executive boards, legislatures or committees. Even the main agents in introductory economic textbooks, e.g., households and firms, are typically not individuals, but groups of people with a joint stake in economic decisions. The range of decisions taken by teams is wide, including, for example, market entry decisions of companies or savings and investment decisions of households. Risk is necessarily an important dimension of such decisions. Therefore, the recent literature on group decision-making has put a strong emphasis on group decision-making under risk. Since observing and identifying the influence of group decision-making on risky choices is difficult with field data (see Prather and Middleton, 2002, for an exception using data from mutual fund management), most of this literature has used laboratory experiments to explore group decision-making under risk (e.g., Baker et al., 2008; Shupp and Williams, 2008; Masclet et al., 2009). In these experiments, subjects are randomly assigned to groups and are then requested to make a group decision (either by talking to each other or by voting within a group). Typically, groups are found to have a smaller variance in their risk preferences than individuals. Concerning the question of whether groups are more or less risk-averse than individuals, the general evidence seems to suggest that groups are more risk-averse in lotteries with low probabilities of winning the largest payoffs, but less risk-averse when these probabilities are high (e.g., Baker et al., 2008; Shupp and Williams, 2008; Masclet et al., 2009). This pattern is consistent with group choices being closer to what would be expected of rational, risk-neutral decisions in risk experiments. This matches the general finding from experimental research on group decision making that groups are more rational agents than single individuals (Cooper and Kagel, 2005; Kocher and Sutter, 2005).

One potential problem of group decision-making research concerns the formation of groups, though. In the studies referred to above, groups are formed by randomly assigning subjects who don't know each other to a specific group. This raises the question of whether more naturally occurring groups with a longer history behave in the same way as artificially created ad-hoc groups. In a nutshell, the question concerns the external validity of group research with randomly assigned groups. A recent strand of literature has tried to examine this 
question by studying the decision-making of couples, some of them married for several decades, that are drawn from the general population (e.g., Bateman and Munro, 2005; Carlsson et al., 2009; de Palma et al., 2011). While this approach is highly welcome, it is difficult to compare the results from these latter studies with the controlled laboratory experiments with randomly assigned groups because two features have been simultaneously changed (the subject pool - students versus subjects from the general population - and the group formation - randomly assigned ad-hoc groups versus natural groups with a history), confounding attempts to draw inferences about the external validity of randomly assigned groups.

In this paper, we contribute to the literature on group decision-making by running an experiment with student couples. Thus, we keep the subject pool comparable to earlier studies with randomly assigned ad-hoc groups, but we investigate natural groups in the sense that we consider couples who have been cohabitating for 18.5 months on average. By taking this approach, we can check how these couples make risky choices and how their joint decisions relate to their individual decisions. Unfortunately, the previous experimental literature on ad-hoc groups and risky choices has used only three-person groups, nor has it controlled for the gender composition of groups in the analysis of differences between individuals and groups (Baker et al., 2008; Shupp and Williams, 2008; Masclet et al., 2009). Since group formation has been random in these earlier studies, however, the differences between individuals and groups have most probably not been influenced by the gender composition of groups. In our case, groups always consist of one woman and one man.

Section 2 introduces the experimental design. Section 3 presents the results, and section 4 concludes.

\section{Experimental design}

The experiment was conducted with university students in student residential areas around several universities in Guiyang, the capital of an inland province in southwest China. In the experiment, we used the design by Holt and Laury (2002), asking subjects to make 10 
sequential choices between one "safe" option A (with payoffs of 16 or 20 Yuan) and one "risky” option B (with payoffs of 1 or 38.5 Yuan), with probabilities of higher payoffs increasing from $10 \%$ to $100 \%$, as illustrated in Table 1.

\section{Table 1 about here}

We recruited 100 cohabitant student couples (100 males and 100 females) by randomly knocking on doors in student residential areas. After obtaining agreement from both partners on a time to conduct the experiment, an experimenter arrived at their apartment and conducted the experiment. First, couples were asked to make 10 choices individually (in different corners of a room with their backs towards each other; they were not allowed to talk to each other in this part), and, second, they made the same choices jointly by talking to each other, and agreeing on each decision in the ten choices. The subjects were not made aware of the second part before they had completed their individual decisions. ${ }^{1}$ At the end of the experiment, subjects were paid for both parts of the experiment by randomly picking one choice each from the individual part and one from the joint part. On average, subjects earned 49 Yuan plus a 10 Yuan participation fee (approximately 8.3 USD at the time of the experiment).

\section{Experimental results}

Figure 1 illustrates the fraction of subjects choosing the relatively safe option A in each choice situation. $^{2}$ Panel (a) distinguishes between the choices of males, females, and couples. The dashed line represents the prediction for a risk-neutral, payoff-maximizing decision maker. We see that females are clearly more risk averse than males $(p<0.05$; two-sided

\footnotetext{
${ }^{1}$ A similar sequential procedure was also used in Baker et al. (2008), where no order effects were found when the authors controlled for it. Hence, we have not varied the order of decisions in our experiment, meaning that individual decisions are always taken before the group decisions.

${ }^{2}$ We have excluded data from 8 households either because one of the partners or because the couple together made inconsistent choices (by switching back and forth between option A and option B). The following analysis is therefore based on data from 92 households (i.e., 184 subjects).
} 
Mann-Whitney U-test), which is a fairly robust result in the literature (see e.g., Croson and Gneezy, 2009). The joint choices of couples are almost always in between the male and female frequencies of choosing option A, and they are significantly different both from male and female choices ( $p<0.05$; two-sided Wilcoxon signed ranks tests). Panel (b) indicates that the joint choices are practically indistinguishable from individual choices when male and female choices are pooled ( $p=0.92$; two-sided Wilcoxon U-test). These main findings are also supported by Table 2 that reports overall averages of safe choices and the corresponding standard deviations. It is worth noting that the variance of risk preferences is smaller for couples than for pooled individuals ( $p<0.01$; Levene F-test), probably because couples will average out the more risk-averse women and more-risk loving men.

Figure 1 and Table 2 about here

In the following, we present a random effects probit regression analyzing the probability of choosing the "safe choice" (i.e., option A). We present two models, one including only individual choices of males and females to examine gender differences, and one that compares the decisions of couples with individual choices. Model (1) shows that the "probability of winning the high payoff” has a significantly negative impact on the likelihood of choosing the safe option. Males are significantly less risk-averse than females. We also consider an interaction variable between the probability of winning the higher payoffs and male choices in order to see whether gender differences depend on the probability of winning the high payoffs. This, however, is shown not to be the case at conventional levels of significance. Model (2) adds the couple data to model (1). Again, the probability of winning the higher payoff is significantly negative. The dummy variable for "couple" has a significantly positive sign (with individual decisions of men and women as the benchmark), while the interaction term "Probability*couple" (which ranges from 0.1 to 1.0 for couples) is significantly negative. Taking both variables together, it follows that couples are more risk-averse than individuals when the probability of the higher payoffs is low, but less 
risk-averse when it is high. This implies that couples are closer to the prediction under risk-neutrality than individuals (see also Figure 1).

Table 3 about here

\section{Conclusion}

We have run an experiment on group decision-making by letting cohabitating student couples make risky choices. This has enabled us to study decision-making of long-standing groups with a history of cohabiting for 18 months on average. In line with previous findings (e.g., Masclet et al., 2009), we have found that both individuals and couples are, on average, risk-averse in their choices and that risk preferences are less diverse across groups (i.e., couples) than across individuals. Couples are generally more risk averse than individuals in lotteries with a low probability of winning, but less risk averse when the probability of winning higher payoffs is high. This is very similar to findings in Baker et al. (2008) who had used randomly assigned groups to study group decision-making under risk. Our paper has shown that naturally occurring groups with a joint history (i.e., student couples) show practically the same choice pattern, lending faith to the external validity of group decision-making research that relies on randomly assigned ad-hoc groups. 


\section{References}

Baker, R.J., Laury, S. K., Williams, A. W. (2008), “Comparing group and individual behavior in lottery-choice experiments.” Southern Economic Journal 75: 367-382.

Bateman, I., Munro, A. (2005), “An experiment on risky choice amongst households.” Economic Journal 115(502): C176-C189.

Carlsson, F., Martinsson, P., Qin, P., Sutter, M. (2009), "Household decision making and the influence of spouses' income, education, and communist party membership: A field experiment in rural China.” IZA Discussion Paper No. 5127.

Cooper, D., Kagel, J. (2005), “Are two heads better than one? Team versus individual play in signaling games.” American Economic Review 95: 477-509.

Croson, R., Gneezy, U. (2009), “Gender differences in preferences.” Journal of Economic Literature 47: 448-474.

de Palma, A., Picard, N., Ziegelmeyer, A. (2011), "Individual and couple decision behavior under risk: Evidence on the dynamics of power balance.” Theory and Decisions 70: 45-64.

Holt, C.A., Laury, S. K. (2002), "Risk aversion and incentive effects.” American Economic Review 92: 1644-1655.

Kocher, M., Sutter, M. (2005), “The decision maker matters: Individual versus team behavior in experimental beauty-contest games.” Economic Journal 115: 200-223.

Masclet, D., Colombier, N., Denant-Boemant, L., Loheac, Y. (2009), “Group and individual risk preferences: A lottery-choice experiment with self-employed and salaried workers.” Journal of Economic Behavior and Organization 70: 470-484.

Prather, L. J., Middleton, K. L. (2002), “Are N+1 heads better than one? The case of mutual fund managers.” Journal of Economic Behaviour and Organization 47: 103-120.

Shupp, R.S., Williams, A.W. (2008), "Risk preference differentials of small groups and individuals.” Economic Journal 118: 258-283. 


\section{Tables and Figures}

Table 1. The ten paired lottery-choice decisions.

\begin{tabular}{|c|c|c|c|c|c|c|c|c|c|}
\hline \multirow[b]{2}{*}{ Choice } & \multicolumn{4}{|c|}{ Option A } & \multicolumn{4}{|c|}{ Option B } & \multirow{2}{*}{$\begin{array}{l}\text { Expected payoff } \\
\text { difference } \\
\text { (A - B) }\end{array}$} \\
\hline & $\begin{array}{l}\text { Prob. } \\
\text { (p) }\end{array}$ & $\begin{array}{l}\text { Payoff } \\
\text { (yuan) }\end{array}$ & $\begin{array}{l}\text { Prob. } \\
\text { (1-p) }\end{array}$ & $\begin{array}{l}\text { Payoff } \\
\text { (yuan) }\end{array}$ & $\begin{array}{l}\text { Prob. } \\
\text { (p) }\end{array}$ & $\begin{array}{l}\text { Payoff } \\
\text { (yuan) }\end{array}$ & $\begin{array}{l}\text { Prob. } \\
\text { (1-p) }\end{array}$ & $\begin{array}{l}\text { Payoff } \\
\text { (yuan) }\end{array}$ & \\
\hline 1 & $1 / 10$ & 20 & $9 / 10$ & 16 & $1 / 10$ & 38.5 & $9 / 10$ & 1 & 11.7 \\
\hline 2 & $2 / 10$ & 20 & $8 / 10$ & 16 & $2 / 10$ & 38.5 & $8 / 10$ & 1 & 8.3 \\
\hline 3 & $3 / 10$ & 20 & $7 / 10$ & 16 & $3 / 10$ & 38.5 & $7 / 10$ & 1 & 5 \\
\hline 4 & $4 / 10$ & 20 & $6 / 10$ & 16 & $4 / 10$ & 38.5 & $6 / 10$ & 1 & 1.6 \\
\hline 5 & $5 / 10$ & 20 & $5 / 10$ & 16 & $5 / 10$ & 38.5 & $5 / 10$ & 1 & -1.8 \\
\hline 6 & $6 / 10$ & 20 & $4 / 10$ & 16 & $6 / 10$ & 38.5 & $4 / 10$ & 1 & -5.1 \\
\hline 7 & $7 / 10$ & 20 & $3 / 10$ & 16 & $7 / 10$ & 38.5 & $3 / 10$ & 1 & -8.5 \\
\hline 8 & $8 / 10$ & 20 & $2 / 10$ & 16 & $8 / 10$ & 38.5 & $2 / 10$ & 1 & -11.8 \\
\hline 9 & $9 / 10$ & 20 & $1 / 10$ & 16 & $9 / 10$ & 38.5 & $1 / 10$ & 1 & -15.2 \\
\hline 10 & $10 / 10$ & 20 & $0 / 10$ & 16 & $10 / 10$ & 38.5 & $0 / 10$ & 1 & -18.5 \\
\hline
\end{tabular}

Note: One USD was equal to 7.1 Yuan at the time of the experiment.

Table 2. Descriptive statistics.

\begin{tabular}{lcccc}
\hline \hline Number of & & & & \\
safe choices & Male & Female & Individual pooled & Group \\
(Option A) & & & & \\
\hline Mean & 4.48 & 5.25 & 4.86 & 4.84 \\
Median & 4 & 5 & 5 & 5 \\
Std. Dev. & 1.90 & 1.69 & 1.83 & 1.56 \\
\hline
\end{tabular}


Table 3. Random effects probit regression results for probability of safe choice

\begin{tabular}{lcc}
\hline \hline Variables & Model (1) & Model (2) \\
\hline Probability of winning the high payoff & $-44.251^{* * *}$ & $-46.069^{* * *}$ \\
Male & $(10.000)$ & $(4.058)$ \\
& $-6.301^{*}$ & \\
Probability*male & $(3.445)$ & \\
& 5.653 & \\
Couple & $(5.113)$ & $(2.666)$ \\
& & $-8.553^{*}$ \\
Probability*couple & & $(4.708)$ \\
& & $24.684^{* * *}$ \\
Constant & $25.438 * * *$ & $(2.082)$ \\
\hline Rho (Corr. Coeff.) & $(5.827)$ & 0.986 \\
\hline Observations & 0.982 & $(0.003)$ \\
Number of decision makers & $(0.008)$ & 2,760 \\
\hline \hline
\end{tabular}

Note: The table shows the regression coefficients. ${ }^{* * *}$ denotes significance at the $1 \%$ level, ** at the $5 \%$ significance level, and * at $10 \%$ significance level

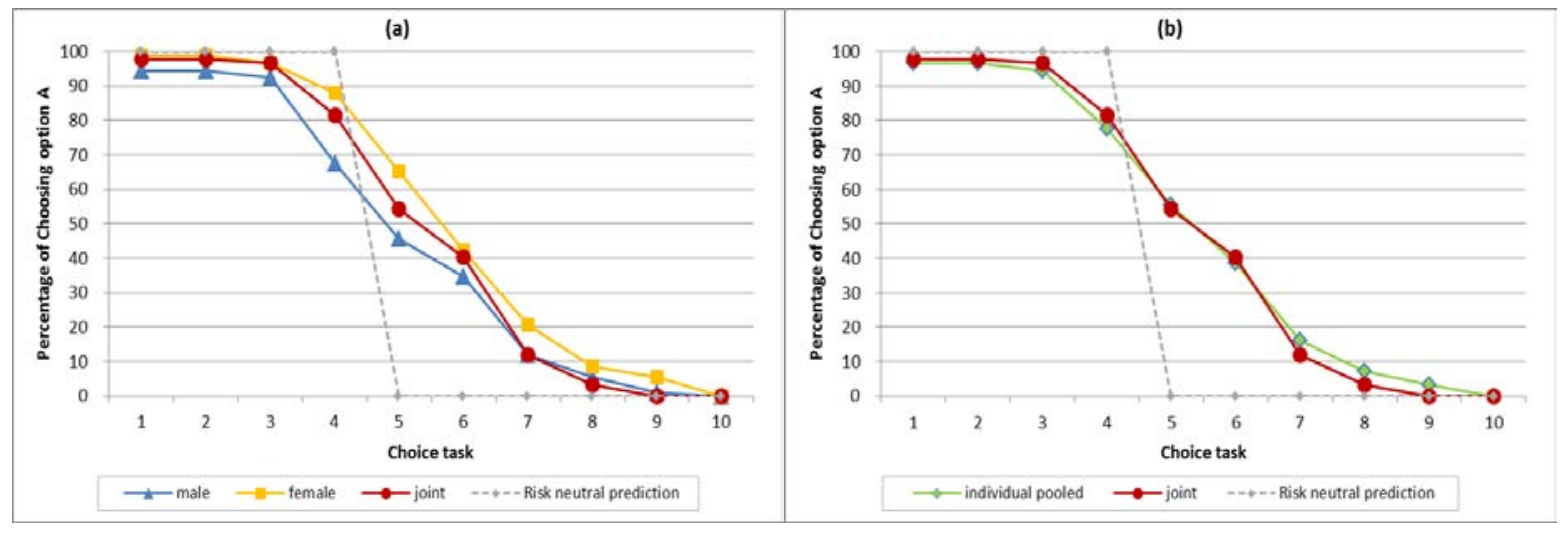

Figure 1. The cumulative distribution of safe choices (of option A). 